\title{
Is air travel safe for those with lung disease?
}

\author{
R.K. Coker, R.J. Shiner and M.R. Partridge
}

ABSTRACT: Airlines commonly report respiratory in-flight emergencies; flight outcomes have not been examined prospectively in large numbers of respiratory patients. The current authors conducted a prospective, observational study of flight outcomes in this group.

UK respiratory specialists were invited to recruit patients planning air travel. Centres undertook their usual pre-flight assessment. Within 2 weeks of returning, patients completed a questionnaire documenting symptoms, in-flight oxygen use and unscheduled healthcare use.

In total, 616 patients were recruited. Of these, 500 (81\%) returned questionnaires. The most common diagnoses were airway (54\%) and diffuse parenchymal lung disease (23\%). In total, 12 patients died, seven before flying and five within 1 month. Pre-flight assessment included oximetry $(96 \%)$, spirometry $(95 \%)$, hypoxic challenge $(45 \%)$ and walk test $(10 \%)$. Of the patients, $11 \%$ did not fly. In those who flew, unscheduled respiratory healthcare use increased from $9 \%$ in the 4 weeks prior to travel to $19 \%$ in the 4 weeks after travel. However, when compared with selfreported data during the preceding year, medical consultations increased by just $2 \%$.

In patients flying after careful respiratory specialist assessment, commercial air travel appears generally safe.

KEYWORDS: Air travel, altitude, chronic obstructive pulmonary disease, hypoxaemia, hypoxic challenge testing

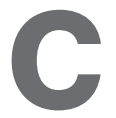

ommercial air travel remains popular despite escalating oil prices, international security and environmental concerns. The number of commercial aircraft passengers with respiratory disease is unknown, but in 1974 $\sim 5 \%$ were described as "ambulatory patients" [1]. As Western populations age, the proportion of passengers with pre-existing morbidity is likely to rise. Longer flights further increase the risk of in-flight medical emergencies.

There are no established methods for quantifying morbidity associated with air travel. However, major airlines consistently report $\sim 10 \%$ of inflight medical emergencies resulting from respiratory conditions. Medaire, a USA company providing radio-link emergency medical assistance to major commercial airlines, cites respiratory conditions as the third most common cause of in-flight medical emergencies [2]. Respiratory problems are also the third most common reason for medical diversion, with the most common being cardiac and neurological conditions (including syncope). In 2002, Medaire recorded 414 diversions for medical emergencies, and in 2006 the cost of an airline diversion was estimated at $\sim$ US $\$ 100,000$ [3].

This article has supplementary material accessible from www.ersjournals.com
Commercial aircraft fly at $\sim 38,000 \mathrm{ft}$, but are pressurised to a cabin altitude of $8,000 \mathrm{ft}$ $(2,438 \mathrm{~m})$. Variations in cabin altitude, up to $2,717 \mathrm{~m}$, have been reported [4]. The reduced alveolar oxygen partial pressure $\left(\mathrm{Pa}_{2} \mathrm{O}_{2}\right)$ at this altitude equates to breathing $15 \%$ oxygen and lowers the $\mathrm{Pa}_{1} \mathrm{O}_{2}$ of a healthy passenger to 7.0 $8.5 \mathrm{kPa}(53-64 \mathrm{mmHg})$. The effect, limited by the shape of the haemoglobin dissociation curve, usually goes unnoticed. However, this exposure may have a profound effect on those with lung disease, especially if they are hypoxaemic at sea level, because the steeper part of the dissociation curve is involved. Other consequences of air travel include immobility, predisposing to venous thrombosis, increased gas volumes, lowered humidity and potential for transmission of infection.

The British Thoracic Society (BTS) recommendations on respiratory disease and air travel were first published in 2002 and updated in 2004 [5, 6]. In the absence of good quality trials, the recommendations suggest that adults with resting oxygen saturations on air at sea level of 92 $95 \%$ and an additional risk factor (such as forced expiratory volume in one second (FEV1) $<50 \%$ predicted) should undergo hypoxic challenge testing (HCT). However, facilities for pre-flight assessment, including HCT, are not universally available in the UK, and at least one major British
AFFILIATIONS

Respiratory Medicine,

Hammersmith Hospitals NHS Trust and National Heart \& Lung Institute, Imperial College London, London, UK.

CORRESPONDENCE

R.K. Coker

Respiratory Medicine Hammersmith Hospital 150 Du Cane Road London W12 OHS UK

Fax: 442083834957

E-mail: robina.coker@imperial.ac.uk

Received:

March 012007

Accepted after revision:

July 252007

SUPPORT STATEMENT

The study was funded jointly by the British Lung Foundation and the British Thoracic Society. The authors are grateful for the support from the UK NIHR Biomedical Research Centre funding scheme.

STATEMENT OF INTEREST None declared. 
airline reports that it is rarely provided with the necessary information to assess risk, such as spirometry or oximetry. The BTS statement, therefore, identified a need to establish the size of the risk from flying, the predictive value of pre-flight assessments and the outcome of air travel in passengers prescribed in-flight oxygen.

To address these questions the current authors undertook the UK Flight Outcomes Study, a prospective, multicentre, observational study aimed at examining the outcomes of commercial air travel for patients with respiratory disease. The authors specifically wanted to determine the magnitude of the risk of air travel for adults with respiratory disease, how best to assess it and whether in-flight oxygen reduces or eliminates the risk.

\section{METHODS}

In total, 58 UK respiratory specialists who had expressed an interest were invited to participate. Patients were eligible if they were under the care of an adult respiratory specialist and planning air travel on a commercial airline. For each patient the recruiting physician completed a Physician Questionnaire (supplementary material, fig. 1) with questions about patients' medical condition, test results and planned date of travel. Patients were excluded if it was felt they would be unable to complete the patient questionnaire, even with assistance, because of language difficulties or psychiatric comorbidity.

Patients were assessed within 3 months of their outward flight according to the centre's usual practice. Pulse oximetry $\left(\mathrm{Sp}, \mathrm{O}_{2}\right)$ and FEV1 were suggested as a usual minimum. If centres usually performed a walk test, HCT and/or diffusing capacity of the lung for carbon monoxide (DL,CO) measurements, or if recent results from these were available, the findings were attached to the questionnaire.

Patients received an information sheet and signed a consent form consenting to transfer of personal details to the principal investigator. Within 2 weeks of the predicted date of their return, patients were sent a Patient Questionnaire (supplementary material, fig. 2) with questions about outward flight, stay abroad, return flight and any complications. Distress during flight was quantified using numbered scales for breathlessness, chest pain and cough. Data were collated centrally for analysis. Reminders were sent to patients who did not respond after 1 month, after checking with the recruiting centre that no untoward incident had occurred.

The questionnaires were employed to determine major and minor outcomes. Major outcomes were defined as the number of patients experiencing distress during flight, the number requiring in-flight assistance, and the number requiring unscheduled use of health service resources within 4 weeks of their outward or return journey. Minor outcomes were defined as the number of in-flight oxygen prescriptions and deaths within 1 month of air travel.

The size of the study took into account the fact that no comparative (control) data were available and that conventional sample size calculations could not be applied. Therefore, analysis was based on descriptive methods. Subgroup analysis of a smaller number of patients compared outcomes in those patients who had undergone HCT and/or received in-flight oxygen. The study received national multicentre research ethics approval (reference No. 03/4/088).

\section{RESULTS}

In total, 37 UK centres participated. Between December 1, 2003 and November 31, 2005, 616 patients were recruited and 500 $(81 \%)$ patient questionnaires were returned after air travel. The mean (range) age was 61 (18-91) yrs; there were 325 males and 291 females. Patients had a wide range of respiratory conditions. The most common diagnoses were airway disease, with asthma and chronic obstructive pulmonary disease (COPD) accounting for 54\%, and diffuse parenchymal lung disease (DPLD), excluding sarcoidosis, accounting for $23 \%$. Table 1 summarises the clinical characteristics of all the patients recruited and table 2 shows the main characteristics of patients who underwent HCT.

Mean (range) $\mathrm{Sp}_{\mathrm{p}} \mathrm{O}_{2}$ was $95(74-100) \%$ on air and mean (range) FEV1 was $58(9-131) \%$ pred. According to the Global Initiative for Obstructive Lung Disease (GOLD) classification [7], 2\% of all the study patients with COPD had mild disease (FEV1 $>80 \%$ pred), $29 \%$ had moderate disease (FEV1 $50-80 \%$ pred), $43 \%$ had severe disease (FEV1 $30-50 \%$ pred) and $26 \%$ very severe disease $(\mathrm{FEV} 1<30 \%$ pred). In the group with COPD who underwent HCT, none had mild disease, $24 \%$ had moderate disease, $46 \%$ severe disease and $30 \%$ very severe disease.

Out of the 616 patients recruited, pre-flight oximetry was available in 594 (96\%) and pre-flight spirometry in $588(95 \%)$. HCT results were available in $275(45 \%)$ and walk-test data in $60(10 \%)$. In total, $85(19 \%)$ of the 500 patients who flew and returned their questionnaire were prescribed in-flight oxygen, of whom $68(80 \%)$ had undergone HCT. HCT was performed in $22(59 \%)$ out of the 37 centres. Only limited gas transfer measurements were available. DL,CO (\% pred) was available in

$\begin{array}{lc}\text { TABLE } 1 \text { Clinical characteristics of study participants } \\ \text { Subjects } & 616 \\ \text { Age yrs } & 61(18-91) \\ \text { Male/female } & 325 / 291 \\ \text { Most common diagnoses } & \\ \text { COPD } & 243(39) \\ \text { Diffuse parenchymal lung disease (excluding sarcoidosis) } & 141(23) \\ \text { Asthma } & 90(15) \\ \text { Bronchiectasis } & 49(8) \\ \text { Sarcoidosis } & 45(7) \\ \text { Less common diagnoses } & \\ \text { Obstructive sleep apnoea syndrome } & 10 \\ \text { Cystic fibrosis } & 5 \\ \text { Pleural disease } & 5 \\ \text { Pulmonary hypertension } & 6 \\ \text { Cancer } & 5 \\ \text { Chest wall disease } & 2 \\ \text { Previous venous thromboembolism } & 1 \\ \text { Other } & 14\end{array}$

Data are presented as $\mathrm{n}$, mean (range) or $\mathrm{n}(\%)$. COPD: chronic obstructive pulmonary disease. 


\begin{tabular}{lc} 
TABLE 2 & $\begin{array}{l}\text { Clinical characteristics of patients who } \\
\text { underwent hypoxic challenge testing }\end{array}$ \\
Subjects $\mathbf{n}$ & 275 \\
Age yrs & $61(18-86)$ \\
Male/female & $140 / 135$ \\
Most common diagnoses & $113(41)$ \\
COPD & $82(30)$ \\
Diffuse parenchymal lung disease (excluding sarcoidosis) & $20(7)$ \\
Asthma & $18(7)$ \\
Bronchiectasis & $12(4)$ \\
Sarcoidosis & \\
\hline & \\
Data are presented as n, mean (range) or n (\%). COPD: chronic obstructive \\
pulmonary disease.
\end{tabular}

only 47 (19\%) out of 243 COPD patients and in 100 (71\%) out of 141 DPLD patients. Therefore, the current authors analysed results only in the DPLD group. The range of $D \mathrm{~L}, \mathrm{CO}$ was $18-93 \%$ pred in the DPLD group, mean $46 \%$ pred. The values did not predict outcome.

Figure 1 summarises the patient outcomes. Of the 616 patients recruited, 69 (11\%) did not fly. Of these, 31 experienced deterioration in their condition beforehand, of whom 19 were advised not to fly by their specialist or general practitioner. The mean (range) age of the latter was 59 (41-75) yrs and there were eight males. Out of these, 13 had COPD, with $62 \%$ having very severe disease according to GOLD criteria. Nine patients experienced difficulties arranging oxygen, reported prohibitive insurance costs, or declined to travel with the recommended oxygen. Two patients reported they could not book charter flights or package holidays because the airlines would not provide oxygen and 20 patients did not fly because of unforeseen changes in personal circumstances.

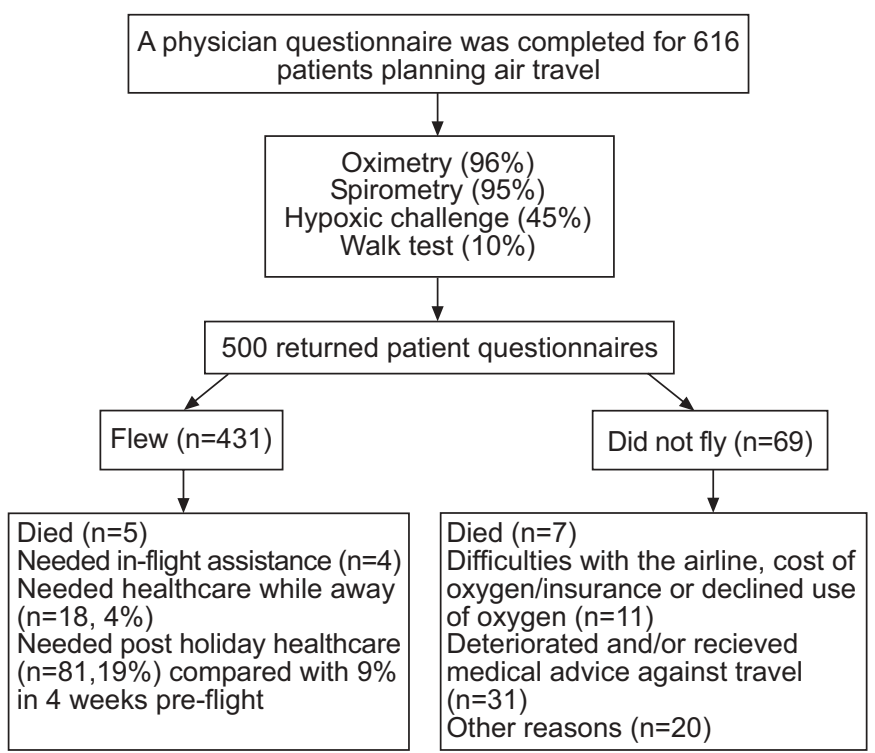

FIGURE 1. Outcomes of the physician questionnaire completed by 616 respiratory disease patients planning air travel.

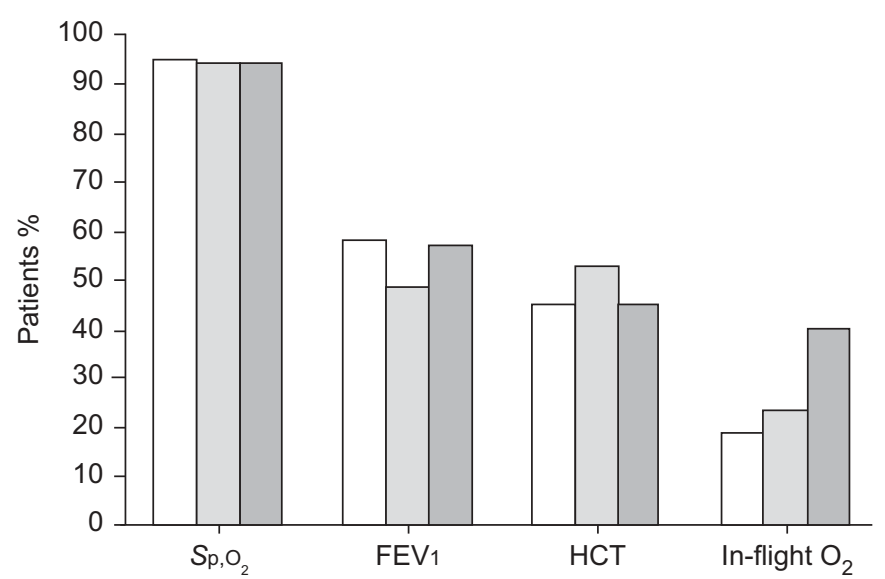

FIGURE 2. Results of arterial oxygen saturation measured by pulse oximetry $\left(\mathrm{Sp}, \mathrm{O}_{2}\right)$, pre-flight forced expiratory volume in one second ( $\mathrm{FEV} 1 ; \%$ predicted), percentage of patients who underwent hypoxic challenge testing (HCT) and overall in-flight oxygen use in patients who either died $(\square)$ or who were admitted to hospital within 1 month of flying $(\square)$. $\square$ : overall group of patients.

Seven patients died before flying, all but one from respiratory causes. Five patients died within 1 month of flying. Two of the patients had COPD as their primary diagnosis, two had DPLD and one had cancer. Two patients died while away following acute cardiac events. One patient had coexisting ischaemic heart disease and peripheral vascular disease; the other had documented hypertension. There were no in-flight deaths. Thus overall mortality within 1 month of air travel was $<1 \%$. Of the three patients who died after returning home, one died of liver cirrhosis, one following rapid recurrence of carcinoma and one during an exacerbation of COPD. Mean pre-flight FEV1 in those who died was $57 \%$ pred, compared with $58 \%$ pred overall. Mean pre-flight $\mathrm{Sp}, \mathrm{O}_{2}$ in those who died was $93 \%$, compared with $95 \%$ overall. Three out of the five patients who died after travel had undergone HCT beforehand, and two had received in-flight oxygen.

In-flight respiratory distress was experienced in $79(18 \%)$ patients. Of these, 38 patients reported distress on both flights and 41 on just one flight. The most common symptom among the 79 patients was worsening breathlessness, reported by 61 (77\%) patients. Thirty-five (44\%) reported cough and $18(23 \%)$ chest pain. Severity of symptoms ranged from mild to moderate. Flight duration averaged $7.6 \mathrm{~h}$ in patients who reported worsening symptoms compared with $6 \mathrm{~h}$ in those who did not. In patients who experienced symptoms on only one flight, symptoms were more common on the return flight than on the outward flight (26 and 15 patients, respectively). Five patients required in-flight assistance, but this was triggered by worsening respiratory symptoms in only one case. This patient received in-flight oxygen which had been ordered in advance as a precaution. There were no flight diversions or emergency repatriations.

In total, 17 patients were admitted to hospital for respiratory illness within 1 month of flying. There were no significant differences in pre-flight observations in this group compared with the group overall (mean pre-flight FEV1 49\% pred compared with $58 \%$ pred overall; mean pre-flight $S \mathrm{p}, \mathrm{O}_{2} 94 \%$ 


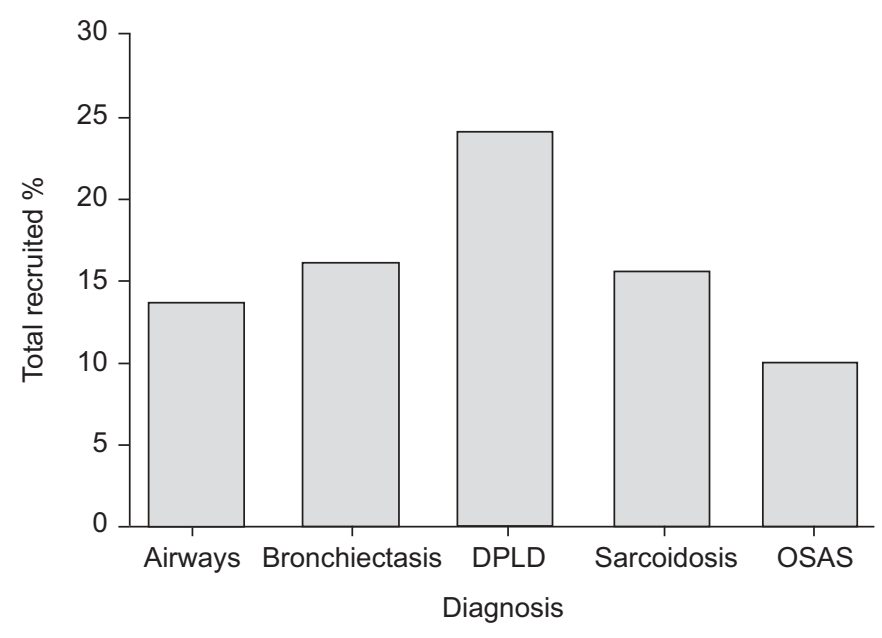

FIGURE 3. Unscheduled healthcare use within 4 weeks of air travel stratified according to the initial primary diagnosis of airways disease, bronchiectasis, diffuse parenchymal lung disease (DPLD), sarcoidosis or obstructive sleep apnoea syndrome (OSAS).

compared with $95 \%$ overall). Nine (53\%) patients had undergone pre-flight HCT compared with $45 \%$ overall, and four $(23 \%)$ had received in-flight oxygen compared with $19 \%$ overall. Figure 2 summarises pre-flight assessment results and in-flight oxygen use overall and in those patients who were admitted to hospital or died within 1 month of flying.

In the 468 patients who undertook flight, the current authors compared the need for unscheduled healthcare for a respiratory problem while away or in the 4 weeks after flying with the 4 weeks before travel. The number of patients who consulted a doctor or required medical treatment rose from $40(9 \%)$ before flying to $81(19 \%)$ within 4 weeks of returning. Of these, 53 $(65 \%)$ reported antibiotic treatment for lower respiratory tract infections. A further 18 patients $(4 \%)$ required unscheduled medical care while away. Although four patients developed symptoms suggesting venous thromboembolism (VTE), there were no confirmed episodes. Patients with DPLD (excluding sarcoidosis) were more likely to require unscheduled healthcare for respiratory events than patients with other diagnoses, including airway disease. Figure 3 shows use of unscheduled healthcare according to diagnosis.

The current authors also compared the need for unscheduled healthcare for respiratory problems with a self-reported baseline during the 12 months preceding air travel. Selfreported baseline figures showed 16 hospital admissions per month compared with 17 admissions within 4 weeks of flying. There were 11 additional hospital admissions while away from home. Visits to a doctor (either in primary or secondary care) were similar; 58 per month in the 12 months preceding air travel (13\%) and 64 in the month afterwards (15\%).

In total, 275 patients underwent HCT, of whom 129 (47\%) were advised to have in-flight oxygen. Analysis of HCT results where complete data were available showed that in 82 patients $(23 \%)$, resting $S_{p}, \mathrm{O}_{2}$ was $\geqslant 96 \%$ beforehand. In $19(23 \%)$ of these patients, partial pressure of oxygen fell to $<6.6 \mathrm{kPa}$ $\left(<50 \mathrm{mmHg}\right.$ ) or $\mathrm{Sp}_{\mathrm{p}, \mathrm{O}_{2}}$ fell to $\leqslant 85 \%$.
Average flight duration was $6 \mathrm{~h}$ (range $1-30 \mathrm{~h}$ ), and was identical in those admitted to hospital within 4 weeks of air travel. Mean flight duration in those who died was $4 \mathrm{~h}$ (range 1-11 h). Most flights were undertaken in the third and fourth quarters of the year.

\section{DISCUSSION}

The most important finding of the current study was that for patients with lung disease flying after careful respiratory specialist assessment, commercial air travel appears to be safe. Overall mortality within 1 month of flying was $<1 \%$, and there was no appreciable increase in use of unscheduled respiratory healthcare in the 4 weeks after travel when compared with self-reported data during the preceding year.

To the current authors' knowledge this is the first prospective multicentre observational study of flight outcomes in large numbers of passengers with respiratory disease, and thus it provides valuable information on morbidity and mortality associated with air travel in this group. The large number of UK centres that took part and of patients recruited suggests, as previously noted, that potential problems associated with respiratory disease and air travel are well recognised [8], as is the need for more substantial evidence on which to base future recommendations. With a few exceptions [9-12], previous studies aimed at determining risk in adult passengers have examined small numbers of patients with COPD [13-22] in the acute setting. They have largely excluded comorbidity and studied stable patients. The present study examined $>240$ patients with COPD prospectively in a real-life setting. As far as the authors are aware it is also unique in including patients with a wide range of respiratory diagnoses, and in attempting to determine outcomes within 1 month of air travel.

Pre-flight assessment was conducted according to individual centres' usual practice and included all methods commonly used in secondary care. It has previously been shown [8] that $<10 \%$ of hospital physicians use regression equations $[13,16$, 21-23]. As anticipated, most patients had $\mathrm{Sp}_{\mathrm{p}} \mathrm{O}_{2}$ measurements. Most of the patients who did not undergo spirometry were assessed for obstructive sleep apnoea syndrome. Walk tests were used infrequently, probably because they are time consuming. This is despite recognition that they test the patient's capacity to increase minute ventilation and cardiac output in response to exercise, and potentially provide useful information on cardio-respiratory reserve [5].

The current authors' previous data show that HCT is performed in over half of specialist referral centres but by $<10 \%$ of respiratory specialists in district hospitals [8]. In the present study HCT was performed in nearly half the patients and in 22 centres. This may suggest an increase in availability of HCT in the UK in the past 7 yrs, but may also be explained by the fact that the respiratory specialists involved were likely to be particularly interested in flying and have more methods of assessment available in their departments. Furthermore, the high number of patients undergoing HCTs reflects, at least in part, patient recruitment by two specialist centres, one a supraregional tertiary referral centre. The severity of COPD patients, with $67 \%$ classed as severe or very severe according to GOLD criteria, reflects recruitment from secondary rather than primary care. There did not appear to be any other major 
differences (sex, diagnosis or severity of COPD) between the patient group overall and those who underwent HCT.

During the flight, $18 \%$ of patients reported respiratory distress; however, its severity was generally mild. It is less surprising that the most common symptom was worsening breathlessness, and patients should probably be forewarned of this risk. The high proportion of patients reporting symptoms may reflect selection bias since such patients were likely to have greater awareness of potential problems associated with air travel. Worsening chest pain in $7 \%$ of passengers suggests, as outlined in the BTS recommendations, that cardiac comorbidity should be considered when assessing patients with respiratory disease before air travel. This is further reinforced by the fact that the only two patients who died while away succumbed to acute cardiac events. Evaluation of patients with cardiovascular disease prior to air travel has recently been reviewed and the risk felt to be low [24]. Specific recommendations include advising patients with an abnormal electrocardiogram to carry a copy of it, and patients with a pacemaker or implantable cardiac defibrillator to carry contact details of the device manufacturers. Comorbidity may confer a greater risk than respiratory disease alone.

Taken together the data are consistent with previous studies $[9-10,12,15,18,20]$ suggesting that air travel is safe for patients with respiratory disease under specialist supervision. Whether this is true for those with respiratory disease not under the care of a specialist respiratory physician is unclear. Study participants are likely to have had a special interest in, and awareness of, the potential adverse effects of air travel. Despite $67 \%$ of the 241 COPD patients who flew being in the severe or very severe GOLD categories, there were no in-flight deaths, and only one patient with COPD died within 4 weeks of returning. There were no episodes of VTE. A relatively high proportion of patients recruited (11\%) did not fly, and over half of these changed their plans on medical advice. Many in this group had severe disease, supporting the view that respiratory specialist assessment is important in preventing complications of air travel in this group.

Referral for pre-flight HCT and recommendation for in-flight oxygen appear to be markers of disease severity, without predicting outcome. FEV1 as per cent predicted did not predict outcome in the present study, and in-flight oxygen did not eliminate the risk from air travel for patients with severe disease. However, owing to the small percentage of complications, a type II error cannot be excluded. In particular, it is likely that the patients who were the most ill received oxygen and were most likely to die or have complications. These results do not therefore support hypoxaemic patients travelling without in-flight oxygen. It is striking that considerable numbers of patients were referred for HCT despite resting oxygen saturations of $\geqslant 96 \%$. According to BTS recommendations these patients do not require HCT or oxygen. Nevertheless, in nearly $25 \%$, arterial oxygen levels fell below the threshold for recommending in-flight oxygen. This suggests that resting $\mathrm{Sp}, \mathrm{O}_{2}$ is not a good predictor of desaturation at altitude; such findings are consistent with those of previous, smaller studies [11, 15, 20]. Further in-flight studies are clearly now required to determine what happens to $\mathrm{Sp}_{\mathrm{p}} \mathrm{O}_{2}$ in flight, and the effect of in-flight oxygen.
The relatively high proportion of patients requiring antibiotics for respiratory tract infections within a month of flying suggests this may be a significant potential complication of air travel in this group. However, there was no control group and factors other than flying, such as travel itself and exposure to different climates, levels of physical activity and new pathogens could be responsible. Further studies are clearly required.

It is reassuring that none of the study patients developed confirmed VTE within 4 weeks of flying. Patients with DPLD were most likely to require unscheduled healthcare for respiratory problems within 4 weeks of air travel (fig. 3). It may be that these patients are not well adapted to hypoxia, that diffusion is disproportionately affected by reduced partial pressure of oxygen at altitude, or that they receive less advice about self-management than patients with COPD.

Recognising that symptoms will develop in this group irrespective of flying, the current authors compared the present results in those who fly with published data on the unscheduled use of health-service resources in comparable patients. A recent study showed that 317 (79\%) out of 400 patients with COPD made unscheduled visits to their general practitioner during $1 \mathrm{yr}$ [25]. Although the level of need in the study patients was higher than this, it was comparable to that recorded in a self-reported baseline during the previous year.

Clearly there are several limitations to the current study. First, patients were chosen because they were under the care of respiratory specialists who had a declared interest in air travel and lung disease. The patient population is thus subject to bias and one should not over-interpret the safety of air travel. Secondly, given the relatively small percentage of complications, it is not possible to say with certainty whether pre-flight spirometry or oximetry, or in-flight oxygen, predict outcomes in this group of patients. Furthermore, owing to the absence of a control group, it is not possible to ascertain whether symptoms reported during air travel were exclusively related to underlying respiratory disease. Finally, the present authors cannot be sure that the present results can be extrapolated to patients flying from other countries, or to patients on somewhat longer flights.

\section{CONCLUSIONS}

The present authors have completed the largest prospective study of air travel in patients with respiratory disease. The current results indicate that air travel is generally safe for patients who are under specialist respiratory care. More detailed studies of patients undergoing full pre-flight assessment, subsequently monitored by oximetry during flight (with and without oxygen as appropriate), may enable us to determine the most useful tests, and the patients most at risk. In the meantime the current study results will be used to inform future British Thoracic Society recommendations on air travel in respiratory disease, and provide reassurance that for those assessed by respiratory physicians with an interest in flight, air travel is relatively safe.

\section{ACKNOWLEDGEMENTS}

The authors wish to thank the following for submitting patients and without whom this study would not have been possible. 
J. Hartley, M. Jackson (Brighton General Hospital, Brighton, UK); M. Hetzel (Bristol Royal Infirmary, Bristol, UK); A. Mier (Chase Farm Hospital, Enfield, UK); A. Dyson (Conquest Hospital, St Leonards-on-Sea, UK); T. Rogers (Doncaster Royal Infirmary, Doncaster, UK); N. Cooke, S. Paramothayan, S. Rahman (Epsom General \& St Helier Hospitals, Epsom and Carshalton, UK); L. Khan (Glenfield Hospital, Leicester, UK); J. Williams (Halton General Hospital, Runcorn, UK); F. Bowen, R. Coker, A. Cummin, S. Gibbs, P. Ind, M.R. Partridge, R. Shiner, S. Shovlin, M. Sridhar (Hammersmith Hospitals, London, UK); A. Arnold (Hull \& East Yorkshire Hospitals, Hull, UK); G. Antunes (James Cook University Hospital, Middlesbrough, UK); I. Connell, T. Cotter, D. Ellis, G. Moorthie, Z. Pond (James Paget Hospital, Great Yarmouth, UK); M. Bradley, M. Henry, M. Muers, S. Pearson, C.B. Pepper, J. Watson (Leeds General Infirmary, Leeds, UK); C. Gelder (Llandough Hospital, Llandough, UK); P. Corris, G. Gibson, B. Higgins, A. Ward (Newcastle-upon-Tyne Hospitals, Newcastle-upon-Tyne, UK); D. Boldy, I. Campbell (Pilgrim Hospital, Boston, UK); O. Johnson (Pontefract General Infirmary, Pontefract, UK); R. Dent (Queen Elizabeth II Hospital, Welwyn Garden City, UK); C. Selby (Queen Margaret Hospital, Dunfermline, UK); P. Beckett (Queen's Hospital, Romford, UK); J. Gravil (Royal Alexandra Hospital, Paisley, UK); S. Packham, C. Davies (Royal Berkshire Hospital, Reading, UK); R. du Bois, F. Chung, S. Durham, D. Geddes, M. Hodson, A. Wells, G. Ladas, D. Mitchell, A. Newman Taylor, M. Polkey, M. Rosenthal, P. Shah, A. Simonds, R. Wilson, D. Cramer (Royal Brompton Hospital, London, UK); P. Howarth (Southampton General Hospital, Southampton, UK); A. Davison (Southend Hospital, Southend-on-Sea, UK); F. Bollery (St John's Hospital, Livingston, UK); C. Bucknall, R. Milroy (Stobhill Hospital, Glasgow, UK); H. Clague, N. Keaney, K. Sridharan (Sunderland Royal Hospital, Sunderland, UK); J. Pepperell (Taunton \& Somerset Hospital, Taunton, UK); L. Dobson (Torbay District General Hospital, Torquay, UK); R. Angus, P. Calverley, L. Davies, P. Davies, J. Earis, C. Warburton (University Hospital Aintree, Liverpool, UK); N. Eiser (University Hospital Lewisham, London, UK); J. Faccenda, R. Fergusson, A. Greening, A. Hill, N. Hirani, A. Innes, T. Mackay, P. Reid, H. Rogers, J. Simpson (Western General Hospital, Edinburgh, UK); S. Quantrill, A. Reinhardt, C. Roberts, R. Taylor (Whipps Cross University Hospital, London, UK); S. O'Hickey (Worcestershire Royal Hospital, Worcester, UK); H. Anderson, A. Jones, C. Leonard, R. Niven, J. Vestbo, A. Woodcock (Wythenshawe Hospital, Manchester, UK); A. Hunter, J. White (York District Hospital, York, UK).

The current authors would also like to acknowledge, with thanks, the assistance and expertise of the clinical scientists in these centres who undertook the physiological assessments. The authors gratefully acknowledge help from L. McNamara, S. Wijetilleka and N. Hawthorne (Hamersmith Hospitals NHS Trust, London, UK) with data collection and processing.

\section{REFERENCES}

1 Iglesias R, Cortes MDCG, Almanza C. Facing air passengers' medical problems while on board. Aerosp Med 1974; 45: 204-206.

2 MedLink Global Response Center. www.medaire.com. Date last accessed: February 2003.
3 Chandler JG.: Diverted Attention. Air Transport World. 2006; p. 30. www.atwonline.com/magazine/article.html/ ?articleID=1582. Date last accessed: April 2007.

4 Cottrell JJ. Altitude exposures during aircraft flying. Flying higher. Chest 1988; 93: 81-84.

5 Coker RK, Boldy DAR, Buchdahl R, et al. Managing passengers with respiratory disease planning air travel: British Thoracic Society recommendations. Thorax 2002; 57: 289-304.

6 The British Thoracic Society. Air Travel Guidelines. www.brit-thoracic.org.uk/page246.html. Date last accessed: February 2006.

7 Rabe KF, Hurd S, Anzueto A, et al. Global strategy for the diagnosis, management and prevention of COPD-2006 Update. Am J Respir Crit Care Med 2007; [Epub ahead of print PMID: 17507545].

8 Coker RK, Partridge MR. Assessing the risk of hypoxia in flight: the need for more rational guidelines. Eur Respir J 2000; 15: 128-130.

9 Kramer MR, Jakobson DJ, Springer C, Donchin Y. The safety of air transportation of patients with advanced lung disease. Chest 1995; 108: 1292-1296.

10 Christensen CC, Ryg MS, Kåre Refvem O, Henning Skjønsberg O. Effect of hypobaric hypoxia on blood gases in patients with restrictive lung disease. Eur Respir J 2002; 20: 300-305.

11 Seccombe LM, Kelly PT, Rogers PG, Lim S, Peters MJ. Effect of simulated commercial flight on oxygenation in patients with interstitial lung disease and chronic obstructive pulmonary disease. Thorax 2004; 59: 966-970.

12 Fischer R, Lang SM, Brückner K, et al. Lung function in adults with cystic fibrosis at altitude: impact on air travel. Eur Respir J 2005; 25: 718-724.

13 Gong H Jr. Tashkin DP, Lee EY, Simmons MS. Hypoxiaaltitude simulation test. Am Rev Resp Dis 1984; 130: 980-986.

14 Dillard TA, Beninati WA, Berg BW. Air travel in patients with chronic obstructive airways disease. Arch Intern Med 1991; 151: 1793-1795.

15 Christensen CC, Ryg M, Refvem OK, Skjønsberg $\mathrm{OH}$. Development of severe hypoxaemia in chronic obstructive pulmonary disease patients at 2,438 $\mathrm{m}(8,000 \mathrm{ft})$ altitude. Eur Respir J 2000; 15: 635-639.

16 Apte NM, Karnad DR. Altitude hypoxaemia and the arterialto-alveolar oxygen ratio. Ann Int Med 1990; 112: 547-548.

17 Schwartz JS, Bencowitz HZ, Moser KM. Air travel hypoxaemia with chronic obstructive pulmonary disease. Ann Intern Med 1984; 100: 473-477.

18 Graham WGB, Houston CS. Short-term adaptation to moderate altitude. Patients with chronic obstructive pulmonary disease. JAMA 1978; 240: 1491-1494.

19 Berg BW, Dillard TA, Derderian SS, Rajagopal KR. Haemodynamic effects of altitude exposure and oxygen administration in chronic obstructive pulmonary disease. Am J Med 1993; 94: 407-412.

20 Akerø A, Christensen CC, Edvardsen, Skjønsberg $\mathrm{OH}$. Hypoxaemia in chronic obstructive pulmonary disease patients during a commercial flight. Eur Respir J 2005; 25: 725-730.

21 Dillard TA, Rosenberg AP, Berg BW. Hypoxaemia during altitude exposure. A meta-analysis of chronic obstructive pulmonary disease. Chest 1993; 103: 422-425. 
22 Dillard TA, Berg BW, Rajagopal KR, Dooley JW, Mehm WH. Hypoxaemia during air travel in patients with COPD. Ann Int Med 1989; 111: 362-367.

23 Henry JN, Krenis LJ, Cutting RT. Hypoxaemia during aeromedical evacuation. Surg Gynecol Obstet 1973; 136: 49-53.
24 Possick SE, Barry M. Evaluation and management of the cardiovascular patient embarking on air travel. Ann Intern Med 2004; 141: 148-154.

25 Britton M. The burden of COPD in the UK; results from the Confronting COPD survey. Respir Med 2003; 97: Suppl. C, S71-S79. 